\title{
Dispatching policy evaluation for transport of ready mixed concrete
}

https://doi.org/10.1515/eng-2020-0030

Received Oct 07, 2019; accepted Nov 12, 2019

\begin{abstract}
Process of ready mixed concrete (RMC) delivery is an example of multi-objective optimization due to the conflicting objectives of the parties involved. In order to face this problem, discrete event simulation model of the delivery process is created with input parameters based on the surveyed data of real processes. The model is simulated with different vehicle dispatching policies and the results are analysed focusing on performance indicators. The research results compared in terms of Pareto optimality indicate that employing effective dispatching strategies can reduce both site idle time and waiting time of vehicles.
\end{abstract}

Keywords: simulation; ready mixed concrete; construction

\section{Introduction}

Ready mixed concrete (RMC) produced in batch plant is a widely used material in construction industry. Along with its advantages it introduces new type of problems related to RMC delivery from the batch plant to the construction site [1]. Delivery is one the key factors for the effectiveness

\footnotetext{
^Corresponding Author: Gabriel Fedorko: Faculty of Mining, Ecology, Process Control and Geotechnology, Technical University of Košice, Letná 9, 04200 Košice, Slovak; Email: gabriel.fedorko@tuke.sk; Tel.: +421-55-602-31-43; Fax: +421-55-602-80-23
}

Michal Weiszer: School of Engineering and Materials Science, Queen Mary University of London, Mile End Road, London E1 4NS, United Kingdom of Great Britain and Northern Ireland;

Email: m.weiszer@qmul.ac.uk

Vieroslav Molnár: Faculty of Manufacturing Technologies with a seat in Prešov, Technical University of Košice, Bayerova 1, 08001 Prešov, Slovak; Email: vieroslav.molnar@tuke.sk

Zuzana Tučková: Faculty of Logistics and Crisis Management, Tomas Bata University in Zlín, nám. T. G. Masaryka 5555, 76001 Zlín, Czech; Email: tuckova@utb.cz

Miloš Poliak: Faculty of Operation and Economics of Transport and Communications, University of Žilina, Univerzitná 8215/1, 01026 Žilina, Slovak; Email: milos.poliak@fpedas.uniza.sk of the inexpensiveness of the whole process. Late arrival of vehicles to the construction site may cause interruptions in concrete placement and idle time of machinery and workers. On the other hand, arrivals of vehicles with short interarrival times result in vehicles queuing on site with idle times of vehicles. Minimization of the idle times of vehicles is not only in the interest of batch plant but also contractor since many vehicles queuing in the construction site is problematic due to limited space, environmental issues and noise mainly in urban areas. Furthermore, RMC must be placed within certain time from the loading in batch plant otherwise it loses its quality and hardens.

In practice, RMC delivery planning is mainly determined by batch plant manager who estimates the vehicles needed for the order and their dispatching interval according to the quantity and delivery time of the concrete specified in the order. Its task is to plan the whole process optimally to ensure utilization of machinery and workers of the batch plant and construction site as well.

This planning process is rather difficult because it is influenced by uncertainty such as changing traffic conditions and concrete placement rate. Well prepared plan together with possible real time operational control of the delivery could maximize utilization of vehicles, minimize their idle times and maximize utilization of machinery and workers on the construction site. Delivery plan also determines the number of vehicles needed to fulfil the order.

In this paper, simulation model of RMC delivery from batch plant to construction site is presented. The model draws from discrete-event simulation methodology and it is applied in a novel way to the RMC delivery process. The contribution of this paper can be summarized as follows. Firstly, the presented model enables to choose optimal vehicle dispatching plan. Rather than selecting single dispatching interval value as presented in previous research [2-4], this paper evaluates several possible options and demonstrates the effect of different dispatching policies [5] on the delivery process. Secondly, the simulation also incorporates feedback from construction site about current situation in delivery. The feedback enables to promptly react to the actual conditions (such as delays in traffic or casting at the construction site) in contrast to

əopen Access. (c) 2020 M. Weiszer et al., published by De Gruyter. (cc) BY 4.0 License

This work is licensed under the Creative Commons Attribution 
the previous research $[6,7]$. Finally, policies with different parameters than in [8] are used in scenarios and are evaluated in terms of Pareto optimality. Optimization treated in this manner takes into account both batch plant and contractors interests namely maximization of vehicle utilization and maximization of construction site machinery and workers.

Firstly, previous research in this field is presented in the next section. Then, process of the RMC delivery is analysed in the following section together with surveyed data from real RMC castings in Slovakia. These processes then serve as a basis for simulation model creation in the fourth section with input data from the survey. Created model is verified and used for scenario evaluation in the fifth section. In the same section, results of simulation for various scenarios and the real process are compared. Finally, conclusions are drawn in the last section.

\section{Previous research}

Production and delivery of RMC from the batch plant to the construction site is an example of JIT process [9]. Several authors employ simulation as a tool for optimization and emphasis is put mainly on time plan of the delivery.

Simulation model with spreadsheet add-in risk analysis tool @Risk is presented by Wang [2]. This model is used to determine the optimal interarrival time of trucks that maximizes the utilization of concrete pump and minimizes the number of trucks needed. More authors [6, 7] combine genetic algorithm (GA) (see [10,11]) with simulation to determine the arrival, departure and waiting time of trucks. GA searches dispatching sequence of trucks from RMC plant to multiple construction sites in order to minimize waiting time of trucks on all construction sites. Combination of Simulation and genetic algorithm is also used by authors [3, 4]. Efficiency of operation in their model is measured by idle times on sites or Total operations inefficiency defined as combination of idle times of trucks, plant and site equipment. Decision variables searched by genetic algorithm are interarrival times of the trucks and their number.

Another authors [8] also focus on truck dispatching interval. However, the truck dispatching interval in their model can vary according to construction manager's response to traffic conditions and RMC placement rate. During the simulation the interval is updated regularly to meet specified objectives (e.g. minimum number of trucks queued at site). Unlike others, they use continuous simulation modelling approach to capture information about work in progress. Results show that responsive scheduling can achieve trade-off between site manager's and RMC supplier's objectives.

RMC distribution has also captured attention of operation research, where researchers see the RMC distribution as a vehicle scheduling problem, order assignment problem (one order can be assigned to multiple plants) [12] or vehicle routing problem [13]. From recent optimization and simulation approaches (e.g. $[14,15])$, local search is used by authors [13], variable neighbourhood search combined with mixed integer programming is proposed by authors [12]. Other works include one by Yan [16, 17] who uses time-space network [18] and [19].

\section{RMC delivery process}

Generic concrete placement process consists of following individual sub-processes:

- vehicle dispatching in batch plant,

- production and discharging of concrete into the vehicle,

- transportation to the construction site,

- unloading of vehicles at the construction site,

- return of vehicles to the batch plant.

In order to build the simulation model, real RMC delivery operations were observed in Bratislava, Slovakia. Four casting operations, each one lasting a whole day, of the same type of structural element being constructed were examined by checking delivery tickets, comprising of 170 individual deliveries (vehicle trips) in total. Obtained data are used in the model as input values.

\subsection{RMC production}

RMC is produced in the batch plant which schedules production according to its capacity and demand. Input raw materials are aggregates, sand, cement, water and additives which are mixed together in the specified proportion to satisfy quality requirements. Observed batch plant has a RMC production capacity of $60 \mathrm{~m}^{3} / \mathrm{h}$.

The production of RMC starts by discharging of individual ingredients into the mixer where they are mixed for specified amount of time. Produced RMC is then loaded into the truck positioned under the mixer. After loading the truck drives to recycling station where excess concrete is washed off.

Truck driver receives a delivery order from plant dispatcher and the truck leaves the batch plant. Survey re- 
sults showed that average time for these processes is $4 \mathrm{~min}$ and the average dispatching interval was $11.66 \mathrm{~min}$. During the survey, no intended dispatching policy was applied.

\subsection{Transportation}

The transportation process is determined by specific properties of RMC. The trucks cycle between the batch plant and construction site until the whole volume of ordered concrete is transported. During transportation, trucks with revolving drums constantly mix the RMC. The main parameter of the vehicles is their capacity. In the observed processes, truck capacity ranged from $5 \mathrm{~m}^{3}$ to $9 \mathrm{~m}^{3}$. Proportion of individual capacities (drum volumes) is shown in Figure 1.

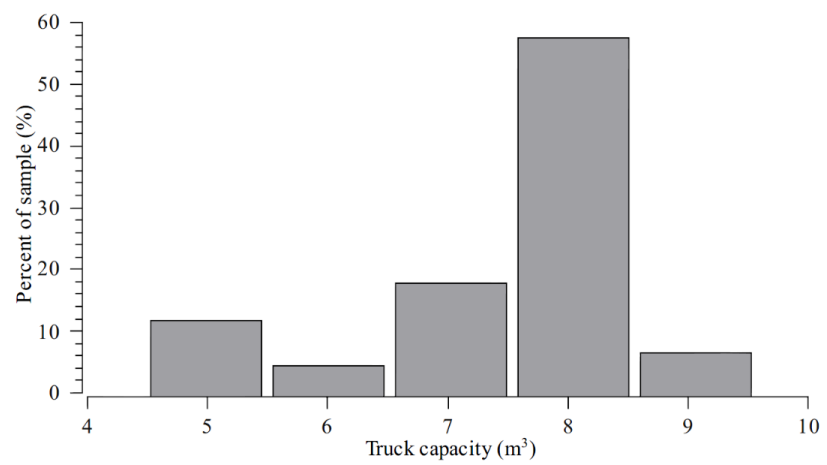

Figure 1: Histogram of truck capacities.

Transportation of RMC is heavily influenced by current traffic conditions such as traffic congestions. In observed processes, average travelling time reached $24.46 \mathrm{~min}$ with standard deviation $5.74 \mathrm{~min}$. The average travelling time takes into account the distance between the plant and the construction site and its stochastic nature reflect the traffic conditions. A normal distribution of travelling time is assumed in this paper based on previous research [20, 21] and empirical fit of the data compared to other distributions. Histogram of surveyed data with fitted normal distribution curve is depicted in Figure 2. Stochastic travelling times cause a deterioration of the initial interval of consecutive vehicles from the batch plant. Therefore, vehicles may arrive at the construction site with different interarrival times.

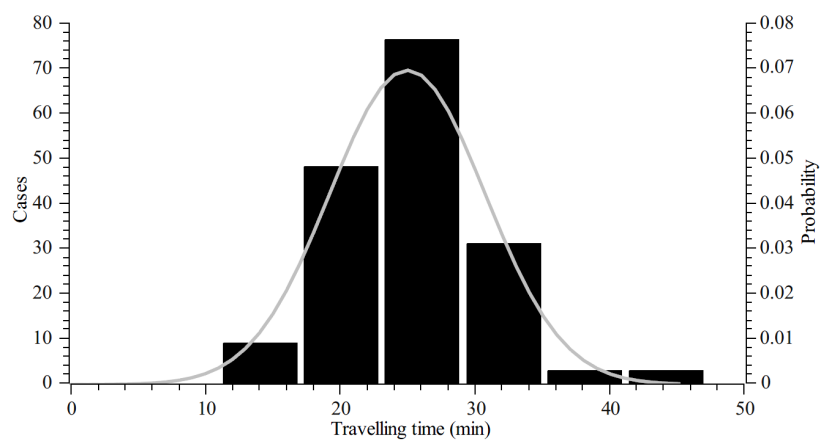

Figure 2: Histogram of travelling time with fitted normal distribution curve.

\subsection{Unloading of RMC}

After the arrival of the vehicle, it waits in a queue until concrete placing machinery (pump) is ready to service it. In observed processes, mobile pump was used with capacity higher than workers capacity to place concrete. Unloading performance determines the time to unload one vehicle. The performance is not constant but varies and it was observed that it was the determining factor affecting the unloading time rather than volume of RMC that vehicle carried (Figure 3). Average unloading time for one vehicle ranged from $5 \mathrm{~min}$ to $20 \mathrm{~min}$. The variation in unloading times is due to the specific factors related to the site such as site layout, height or shape of pouring. After unloading, vehicles return to the batch plant for next delivery.

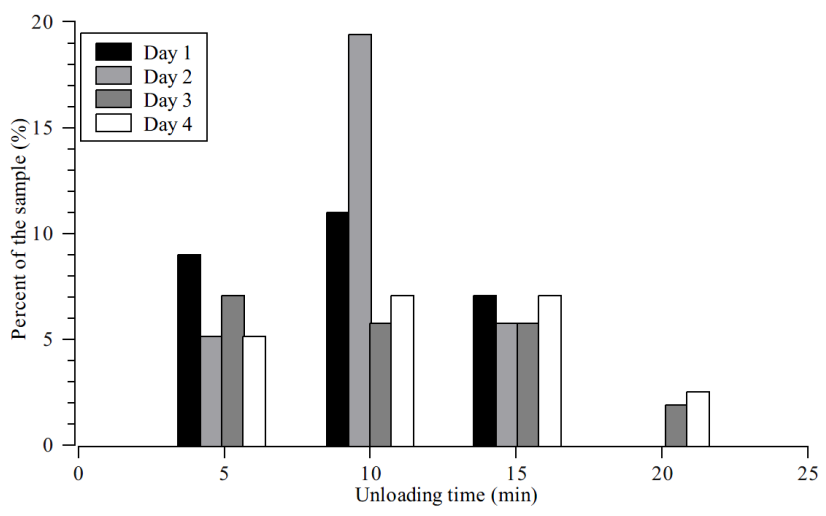

Figure 3: Histogram of unloading times for each day. 


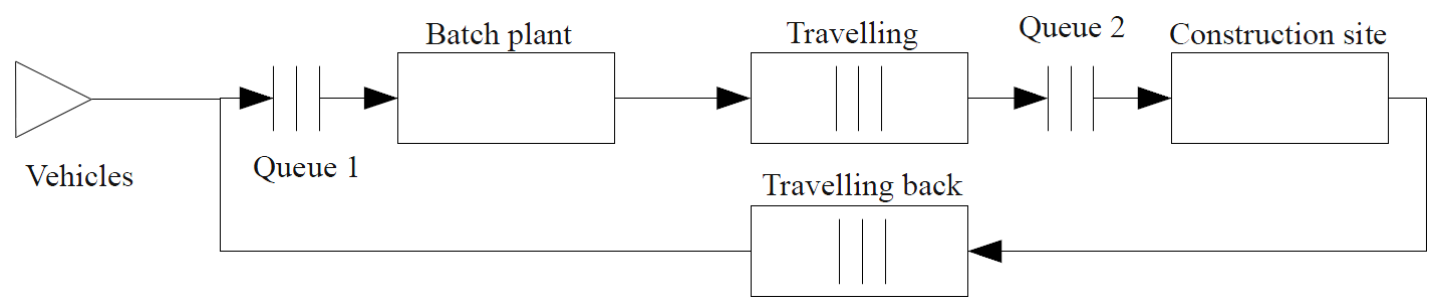

Figure 4: Simulation model scheme.

\section{Model description and methodology}

This paper adopts Discrete-event simulation technique [22] which was implemented in Extendsim simulation package.

The basic structure of the simulation model of the RMC delivering process is depicted in Figure 4. The simulation begins with the generation of the vehicles. Resource of vehicles is a resource block from which the vehicles are drawn into the Queue 1. Queue 1 is a First-in-first-out type with priority for used vehicles. This ensures that vehicles which returned from the delivery are the first one to be used. This way, only the number of vehicles needed is present at the time in the simulation model. New vehicle is sent to delivery if there is no returned vehicle in the Queue 1.

The batch plant is modelled as a single server activity. The service time is equal to the required dispatching interval. It is assumed, that during this time, all activities taking place in the batch plant (mixing, loading, washing) are completed. Vehicles have their attribute of concrete quantity updated. Separate attribute from vehicle capacity is used, since last vehicle may be assigned lower quantity of concrete than its capacity. During simulation, the quantity of produced and loaded RMC is summed. When the sum is equal to the ordered quantity, batch plant stops servicing vehicles.

Infinite server represents travelling from the batch plant to the construction site. Each vehicle receives service with processing time equal to the travelling time. Travelling time is generated as a random number with normal distribution, mean and standard deviation obtained from surveyed data.

Vehicles which arrived to the construction site queue up in the Queue 2 waiting to be unloaded. Since only one vehicle at the time can be unloaded, unloading process is modelled as a single server. For analytical purposes, there is an assumption of no maximum waiting time for vehicles after the RMC loses its quality. Such a constraint would be important particularly in extreme weather conditions (cold or hot). However, the data used in this study was obtained during normal weather conditions.

Empty vehicles travel back to the batch plant for next deliveries. The simulation ends with the last vehicle departing from the construction site when the quantity of ordered RMC is transported.

\subsection{Pareto optimality}

In this study, we consider the minimization of 1) construction site idle time which is mainly the interest of the contractor and 2) waiting time of vehicles which is a concern for the batch plant. As explained in Section 1, high values of construction site idle time and waiting times of delivery vehicles cause inefficiencies for both construction site and batch plant, respectively. In contrast with single-objective problems, multi-objective optimization problems have to deal with more objectives at the same time. Since optimization of the decision variable with respect to just one objective can often lead to worse results in other objectives, simultaneous approach is needed and single solution to multi-objective problem often does not exist at all.

Therefore, the aim of multi-objective optimization is to find a set of solutions each of which minimizes the objective functions at an acceptable level. Predominant concept in determining an optimal solution in multi-objective applications is Pareto optimality [11, 23-28]. In this concept, solutions can dominate each other.

A solution $\mathrm{x}_{1}$ is said to dominate the other solution $\mathrm{x}_{2}$, if:

1. The solution $\mathrm{x}_{1}$ is no worse than $\mathrm{x}_{2}$ in all objectives. Thus, the solutions are compared based on their objective function values, and

2. The solution $\mathrm{x}_{1}$ is strictly better than $\mathrm{x}_{2}$ in at least one objective.

Solution, that is not dominated by any other solution in solution space is called Pareto-optimal. A Paretooptimal solution cannot be improved in any objective without worsening in at least one other objective. The all 
non-dominated solutions in solution space constitute the Pareto optimal set. The corresponding objective functions values of the Pareto-optimal set in the objective space form a Pareto front.

\section{Computational results}

\subsection{Verification and validation of the model}

Reliability of the simulation model can be verified by comparing actual surveyed data and the model output. The model was simulated 100 times for each day with input data based on survey results. Several performance output parameters were collected as summarized in Table 1. The surveyed data and simulation results are not identical due to the stochastic nature of the process and possible survey bias. For example, the average of surveyed site idle time is $30 \mathrm{~min}$ and simulated result is $52.15 \mathrm{~min}$. When compared to the average duration ( $533.75 \mathrm{~min}$ and $516.78 \mathrm{~min}$ ), the site was idle for $5.62 \%$ of time for the surveyed data and $10.09 \%$ for the simulation. Similarly, the total average waiting time of vehicles (589.75 $\mathrm{min}$ and $617.08 \mathrm{~min}$ ) is $110.49 \%$ of the duration for surveyed data and $119.41 \%$ for the simulation.

For analytical purpose, the model accuracy is sufficient, the simulated results approximate surveyed data and the model can be used for further testing. The simulated results are further referred to as Base case.

\subsection{Simulation results for different dispatching policies}

The model was simulated with the same travelling time distribution, same fleet of vehicles (represented by vehicle capacities) and same unloading time distribution for each day but under different vehicle dispatching scenarios to investigate the effect of individual policies on selected performance criteria.

Firstly, constant dispatching interval of vehicles from the batch plant was employed (Scenario 1). For each day, same value of dispatching interval was used and the test was repeated with increasing value of the dispatching interval. Average of the simulated results of the four days were then compared to each other.

Secondly, variable dispatching interval from the batch plant with feedback from the construction site was adopted. Two cases were simulated, one with queue update time $30 \mathrm{~min}$ (Scenario 2) and the second with $15 \mathrm{~min}$ update time (Scenario 3). The information about the queue length at the construction site serves as an input for simple decision process of modifying the initial dispatching interval. If the queue length at the construction site is greater or equal to two, the interval is increased by one minute. If the queue length is equal to zero, the interval is decreased by one minute. However, it cannot drop below the initial interval. This scenario represents a situation where a construction site manager checks the length of vehicle queue on regular basis and reports back to the batch plant to adjust the dispatching interval accordingly.

Finally, variable dispatching interval from the batch plant with 30 min update about the queue length from the construction site was used (Scenario 4). In contrast with previous scenarios, in this case the dispatching interval could go below the initial value. The simulation results are summarized in Table 1.

The simulation results confirmed that the dispatching interval has significant impact on all output performance indicators. Longer dispatching interval caused increase in duration of the process in all scenarios. This is mainly due to higher site idle times with high dispatching interval values when the construction site has to wait for vehicles and concrete placement is interrupted. On the other hand, if the dispatching interval is short, vehicles tend to queue at the construction site and high vehicle idle times can be observed. The queueing of vehicles in case of a short interval is shown in Figure 5. A comparison of vehicle waiting time for different intervals is in Figure 6.

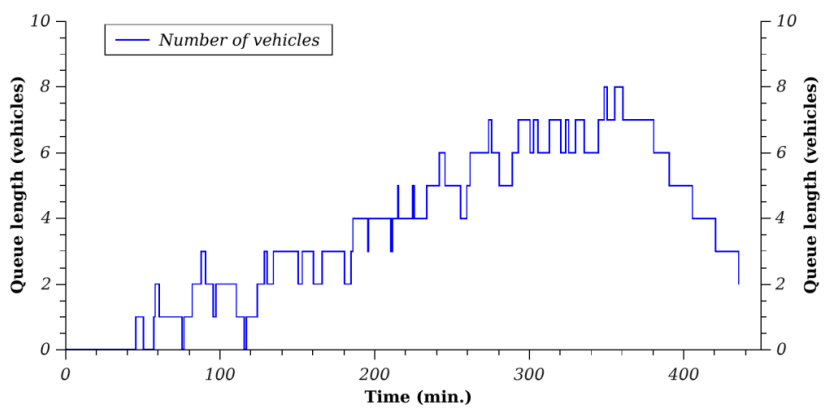

Figure 5: The length of vehicle queue at the construction site (day 4, constant interval $10 \mathrm{~min}$ )

The results also confirmed that there is a trade-off between site idle time and vehicles idle time. Moreover, the results imply that number of vehicles needed to complete the order is related to the dispatching interval. With longer dispatching interval, it was possible to transport the ordered volume of RMC with less vehicles than in the case with shorter dispatching interval. 


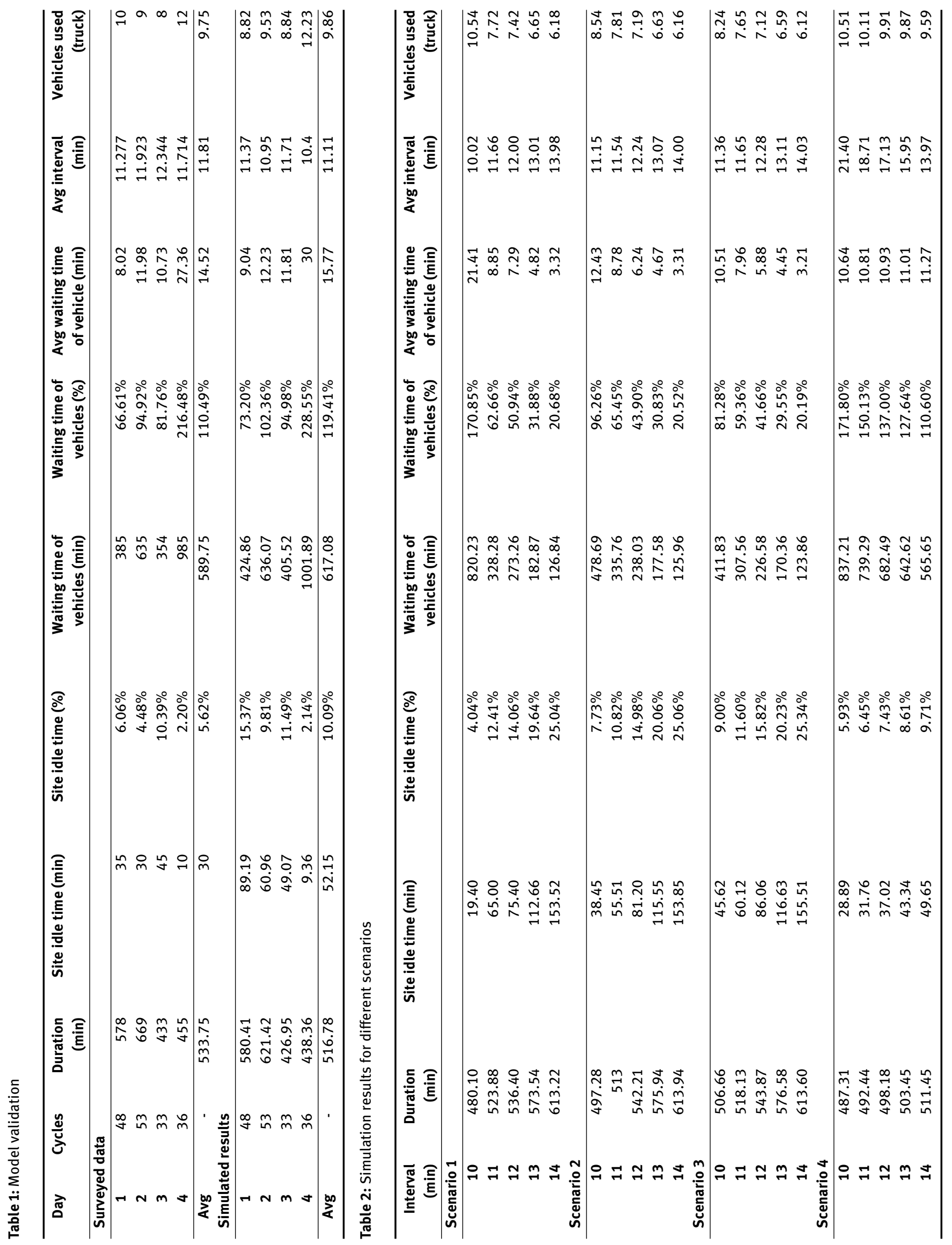




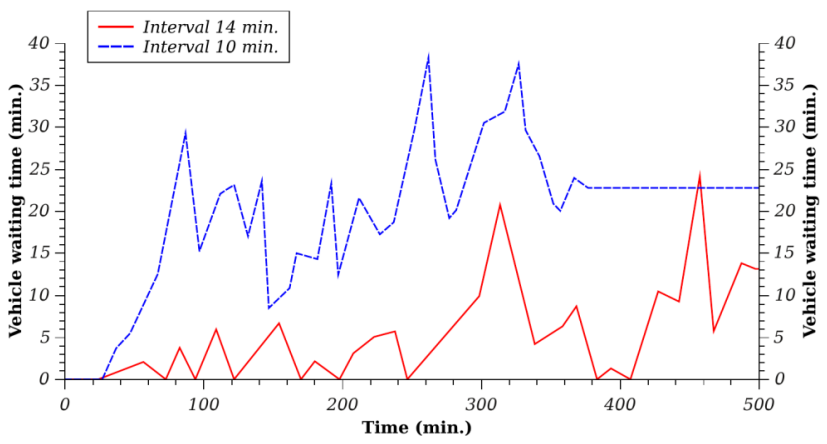

Figure 6: Vehicle waiting time at the construction site, day 1, constant interval

As mentioned in Subsection 4.1, in multi-objective optimization problems, single optimal solution may not exist at all. However, a list of a few solutions in terms of Pareto optimality could be very helpful for the decision maker.

Based on his or her preferences, the decision maker could choose the right trade between conflicting objectives. Comparison of different dispatching policies can be made by evaluating the relationship between site idle times and vehicle idle times. The simulation results for these two performance indicators are compared in Figure 5. The data points are labelled with value of the dispatching interval.

Scenario 2 and 3 with variable dispatching interval with 15 and 30 min update times when decrease below the initial interval is not allowed show similar results in comparison with constant dispatching interval case with higher interval values (13 and $14 \mathrm{~min}$ ). This is due to the fact that with higher intervals, queue length is often equal to zero and the model tries to decrease the interval by one minute. However, since decrease below the initial interval is not allowed, the interval stays the same resulting in the same behaviour as with constant interval policy.

The policy with variable dispatching interval with 30 min update time when decrease below the initial interval is allowed used in Scenario 4 showed poor performance in vehicle idle times for all interval values. This could be due to high uncertainty associated with travelling times and long distance between batch plant and construction site resulting in long time to adjustment of the interval to make an effect. The uncertainty is therefore an important factor and not considering it could compromise the planned schedule [6,7]. The comparison of Scenario 2 and 4 is depicted in Figure 7 and 8, respectively. Scenario 4 enabled low values of dispatching interval which resulted in a long vehicle queue early on (around time $100 \mathrm{~min}$.) in contrast to Scenario 2. As can be seen in

Figure 7, when no decrease below initial interval was allowed, this initial value prevented the dispatching inter- val from low values and higher vehicle idle times associated with them. These observations indicate although the feedback could effectively react to uncertainties, in contrast to [8], a more sophisticated policy such as presented in this paper is needed to achieve a better

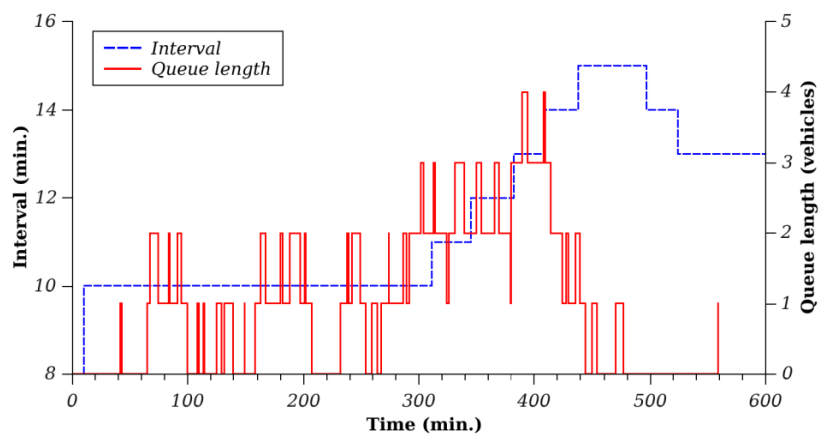

Figure 7: Interval and vehicle queue length for Scenario 2, for day 1 , Initial interval $10 \mathrm{~min}$

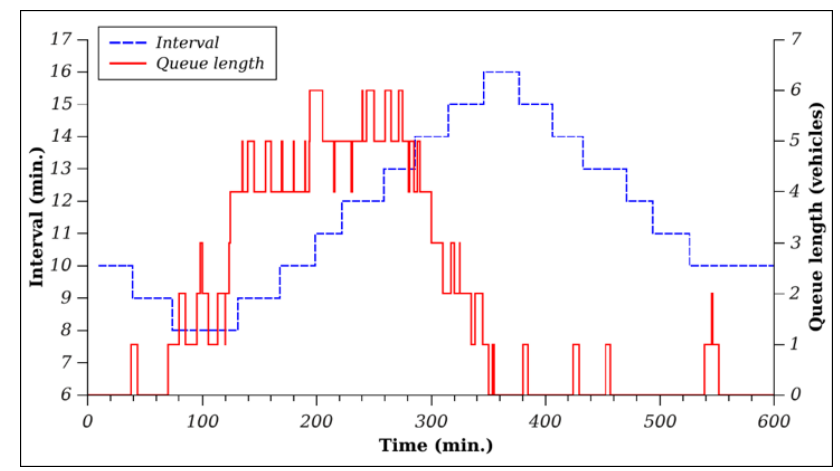

Figure 8: Interval and vehicle queue length for Scenario 4, for day 1, Initial interval $10 \mathrm{~min}$

The greatest improvement in performance indicators of Scenarios 2 and 3 in comparison with constant interval Scenario 1 is achieved with 10, 11 and 12 min dispatching interval. Considering fitted splines (Figure 9), points for variable interval scenarios dominate the constant interval points in the left part of the graph. These results indicate that even if the interval is optimised such as in the previous research [2-4], a constant interval policy is outperformed by a policy with feedback. Variable dispatching interval policy used in Scenario 3 with initial interval of 11 min enabled to improve the site idle time by $7.60 \%$ and vehicles idle time by $6.31 \%$ compared to constant interval policy in Scenario 1.

In all scenarios, applied policies achieved better values of performance indicators than in Base case. The sim- 
ulation results indicate that suitably chosen dispatching policy can reduce waiting time of vehicles and site idle time in the same time.

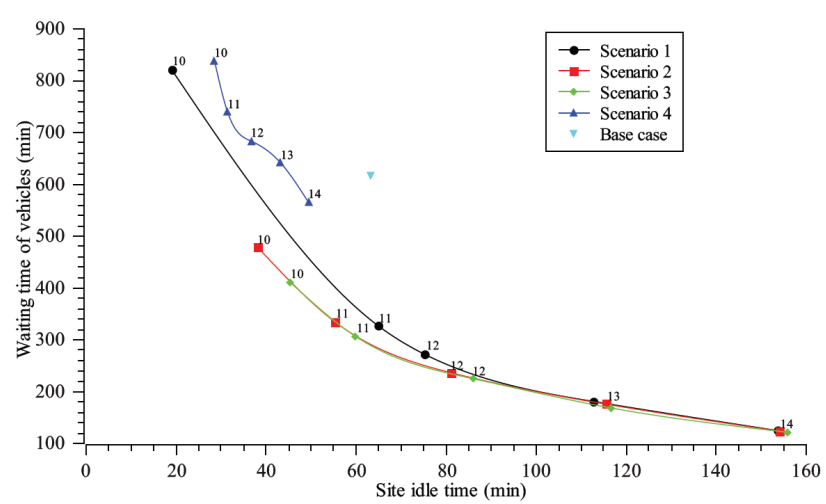

Figure 9: Comparison of simulation results and Pareto fronts

\section{Conclusion}

Managing real world RMC delivery process is a challenging task due to the uncertainty involved. Furthermore, participating partners have different and conflicting objectives. Developed discrete event simulation model tries to improve the whole process by simultaneously minimizing waiting time of vehicles and site idle time. To achieve such effect, various dispatching policies were employed and their results investigated. Comparison of the simulated performance indicators in terms of Pareto optimality showed that variable dispatching interval adjusted according to the feedback from the construction site without decreasing below the initial interval value performed better than other policies including constant interval dispatching. Moreover, variable and constant dispatching interval achieved improvement in both performance indicators compared to the base case.

Although the simulation model was created with input data based on survey of real processes, it can be adapted to different operation conditions by modifying the input values. The simulation model could be then used as a decision supporting tool for selecting the suitable dispatching policy for the RMC delivery process. Similarly, an estimation of number of vehicles needed for the order could be made based on simulation results. Rather than searching for single optimal dispatching interval value, exploring Pareto optimal solutions as in this research helps the decision maker to investigate various scenarios. This way a trade-off between different objectives can be made.
The future research could investigate more sophisticated methods of controlling dispatching interval of vehicles incorporating feedback from the construction site. Collecting further data could also improve the accuracy of the model. Finally, a real-world testing of the proposed controlling policy would help to gather valuable feedback and fine-tune the model.

Acknowledgement: This work is a part of these projects VEGA 1/0600/20, VEGA 1/0403/18, KEGA 012TUKE-4/2019, KEGA 013TUKE-4/2019, APVV SK-SRB-18-0053.

\section{References}

[1] Schmid V, Doerner KF, Hartl RF, et al. A Hybrid Solution Approach for Ready-Mixed Concrete Delivery. Transp Sci 2009; 43: 70-85.

[2] Wang $\mathrm{SQ}$, Teo $\mathrm{CL}$, Ofori $\mathrm{G}$. Scheduling the truckmixer arrival for a ready mixed concrete pour via simulation with @risk. J Constr Res 2001; 2: 169-179.

[3] Lu M, Lam H-C. Simulation-optimization integrated approach to planning ready mixed concrete production and delivery: validation and applications. In: Winter Simulation Conference. 2009, pp. 2593-2604.

[4] Lu M, Lam H-C. Optimized concrete delivery scheduling using combined simulation and genetic algorithms. In: Proceedings of the Winter, pp. 2572-2580.

[5] Kleywegt AJ, Papastavrou JD. Acceptance and Dispatching Policies for a Distribution Problem. Transp Sci 1998; 32: 127-141.

[6] Feng C-W, Cheng T-M, Wu H-T. Optimizing the schedule of dispatching RMC trucks through genetic algorithms. Autom Constr 2004; 13: 327-340.

[7] Feng C-W, Wu H-T. Integrating fmGA and CYCLONE to optimize the schedule of dispatching RMC trucks. Autom Constr 2006; 15: 186-199.

[8] Park M, Kim W-Y, Lee H-S, et al. Supply chain management model for ready mixed concrete. Autom Constr 2011; 20: 44-55.

[9] Tommelein ID, En A, Yi L. Just-in-Time Concrete Delivery: Mapping Alternatives for Vertical Supply Chain Integration. In: Proc. Seventh Ann. Conf. Intl. Group for Lean Constr., IGLC-7. 1999, pp. 26-28.

[10] Guo H, Feng Y, Hao F, et al. Dynamic Fuzzy Logic Control of Genetic Algorithm Probabilities. J Comput 2014; 9: 22-27.

[11] Deb K, Agrawal S, Pratap A, et al. A Fast Elitist Non-dominated Sorting Genetic Algorithm for Multi-objective Optimization: NSGA-II. In: Parallel Problem Solving from Nature PPSN VI. Berlin, Germany, 2000, pp. 849-858.

[12] Schmid V, Doerner KF, Hartl RF, et al. Hybridization of very large neighborhood search for ready-mixed concrete delivery problems. Comput Oper Res 2010; 37: 559-574.

[13] Asbach L, Dorndorf U, Pesch E. Analysis, modeling and solution of the concrete delivery problem. Eur J Oper Res 2009; 193: 820835.

[14] Li S, Karatzoglou A, Gentile C. Collaborative Filtering Bandits. In: Proceedings of the 39th International ACM SIGIR conference on Research and Development in Information Retrieval - SIGIR '16. 
New York, New York, USA: ACM Press, 2016, pp. 539-548.

[15] Kar P, Li S, Narasimhan H, et al. Online Optimization Methods for the Quantification Problem. In: Proceedings of the 22nd ACM SIGKDD International Conference on Knowledge Discovery and Data Mining - KDD '16. New York, New York, USA: ACM Press, 2016, pp. 1625-1634.

[16] Yan S, Lai W, Chen M. Production scheduling and truck dispatching of ready mixed concrete. Transp Res Part E Logist Transp Rev 2008; 44: 164-179.

[17] Yan S, Lin H-C, Liu Y-C. Optimal schedule adjustments for supplying ready mixed concrete following incidents. Autom Constr 2011; 20: 1041-1050.

[18] Lin P-C, Wang J, Huang S-H, et al. Dispatching ready mixed concrete trucks under demand postponement and weight limit regulation. Autom Constr 2010; 19: 798-807.

[19] Naso D, Surico M, Turchiano B, et al. Genetic algorithms for supply-chain scheduling: A case study in the distribution of ready-mixed concrete. Eur J Oper Res 2007; 177: 2069-2099.

[20] Yan S, Lin HC, Jiang XY. A planning model with a solution algorithm for ready mixed concrete production and truck dispatching under stochastic travel times. Eng Optim 2012; 44: 427-447.

[21] Soofastaei A, Aminossadati SM, Kizil MS, et al. A discrete-event model to simulate the effect of truck bunching due to payload variance on cycle time, hauled mine materials and fuel consumption. Int J Min Sci Technol 2016; 26: 745-752.
[22] Sokolowski JA, Banks CM. Principles of Modeling and Simulation: A Multidisciplinary Approach. Hoboken, New Jersey: John Wiley \& Sons, Inc., 2009.

[23] Marler RT, Arora JS. Survey of multi-objective optimization methods for engineering. Struct Multidiscip Optim 2004; 26: 369-395.

[24] Deb K. Multi-Objective Optimization. In: Search Methodologies. Boston, MA: Springer US, pp. 403-449.

[25] Stopka O, Kampf R. Determining the most suitable layout of space for the loading units' handling in the maritime port. Transport 2016; 33: 280-290.

[26] Stopka O, Stopkova M, Kampf R. Application of the Operational Research Method to Determine the Optimum Transport Collection Cycle of Municipal Waste in a Predesignated Urban Area. Sustainability 2019; 11: 2275.

[27] Stopka O, L'upták V. Optimization of Warehouse Management in the Specific Assembly and Distribution Company: a Case Study. Naše more 2018; 65: 266-269.

[28] Lizbetin J, Bartuska L. The Influence of Human Factor on Congestion Formation on Urban Roads. Procedia Eng 2017; 187: 206211. 